\title{
Thyroid Gland Nodule
}

National Cancer Institute

\section{Source}

National Cancer Institute. Thyroid Gland Nodule. NCI Thesaurus. Code C3415.

A nodular lesion that develops in the thyroid gland. Causes include adenoma, thyroiditis,

fluid-filled cyst, multinodular goiter, and carcinoma. 